\title{
The Dyadic Interaction Model of Relationship Quality and the Impact of Attachment Orientation and Empathy on Infertile Couples in China
}

\section{Kun Du}

The First Affiliated Hospital of Zhengzhou University

Yue-zhi Dong ( $\sim$ dyz62295@163.com )

Zhengzhou University First Affiliated Hospital https://orcid.org/0000-0001-6532-1778

\section{Research}

Keywords: Adult attachment, Empathy, Relationship quality, Infertility

Posted Date: October 16th, 2020

DOI: https://doi.org/10.21203/rs.3.rs-90836/v1

License: (c) (1) This work is licensed under a Creative Commons Attribution 4.0 International License.

Read Full License

Version of Record: A version of this preprint was published at Nursing Open on February 25th, 2021. See the published version at https://doi.org/10.1002/nop2.819. 


\title{
The Dyadic Interaction Model of Relationship Quality and the Impact o f Attachment Orientation and Empathy on Infertile Couples in China
}

Running Title: A Dyadic Interaction Model

Kun Du and Yuezhi Dong*

Reproductive Medicine Center, The First Affiliated Hospital of Zhengzhou University, Zhengzhou 450052, China

*Correspondence: dyz62295@163.com

\begin{abstract}
Background: The study was conducted to examine the effect of attachment orientation and empathy on the relationship quality of infertile couples and assess the interdependency model of these factors.

Method: In this study, 168 infertile couples (336 individuals) were enrolled and asked to finish he following questionnaires: the revised Adult Attachment Scales, the Interpersonal Response Index questionnaire, and the Relationship Quality subscale of the Fertility Quality of Life (FertiQol).

Results: The attachment orientation of infertile couples can influence their relationship quality, and empathetic wives and husbands have actor and partner effects on the infertile couples' relationship quality.

Conclusion: Empathetic infertile couples are conducive to the harmony of the relationship. In order to provide better psychological services for patients, the clinical personnel should consider the infertile couple as a team both experiencing the stress of infertility together, and then should evaluate their ability for empathy systematically.
\end{abstract}

Keywords: Adult attachment, Empathy, Relationship quality, Infertility

\section{Plain English summary}

In order to reduce relationship violence and divorce caused by infertility, we focused on the quality of relationships of infertile couples. The main result of this study is that the empathy of infertile couples in 
China not only affects the quality of their own relationships, but also affects the quality of their spouses' relationships. Furthermore, as far as we know, we investigated for the first time the effect of adult attachment orientation on relationship quality in infertile couples in China, and the results showed that both attachment anxiety and attachment avoidance of infertile couples negatively predicted their own relationship quality. The conclusion of this study is that it is beneficial for infertile couples to help them obtain safe attachment relationships. And infertile couples should understand each other and expressing understanding behavior is conducive to the harmony of the relationship.

\section{Background}

Infertility is a disease historically defined by the failure to achieve a successful pregnancy after 12 months or more of regular, unprotected sexual intercourse or due to an impairment of a person's capacity to reproduce either as an individual or with her/his partner [1]. According to the evidence-based results of the 2013 Infertility Survey for Couples of childbearing age in China, 5.7-12.5\% of Chinese couples were suffering from infertility [2]. Although infertility cannot threaten one's life, it can be one of the most stressful events affecting the involved couple's daily life, and the topic of infertility has received extensive attention from researchers around the world. The results of the psychological stress, such as anxiety [3, 4], depression [3, 4] humiliation [5], social exclusion [6], sexual dysfunction [7], sleep disorder [8, 9], and so on were well reported by many researchers; moreover, these psychological disorders bring serious consequences that cannot be underestimated to infertile couples' relationships [10].

As statistics show, the divorce rate for infertile couples is 2.2 times higher than the general population; marital adjustment and marital satisfaction were significantly influenced by the diagnosis of infertility and assistant reproductive therapy in the Chinese population [11]. There are also studies which found that infertility affects the marital bond and leads to poorer resilience, which causes lower scores in relationship quality $[12,13]$. Some quantitative studies found that infertile couple cannot control their lives because infertility is so frustrating [14]. Despite advances in medical technology, it is not worth it for some infertile families to divorce because of infertility before they can get effective help. 
Attachment theory is an integral part of the study of intimate relationship, which was found by John Bowlby from the personality development of inadequate maternal care during early childhood $[15,16]$. With the development of the research, more and more researchers accept attachment avoidance and attachment anxiety as the dimensionality distinguishing methods to describe adult attachment $[17,18]$. According to the description of Donarelli et al. [17]: "Attachment anxiety is defined as involving a fear of interpersonal rejection or abandonment, an excessive need for approval from others, and distress when one's partner is unavailable or unresponsive; Attachment avoidance is defined as involving fear of dependence and interpersonal intimacy, an excessive need for self-reliance, and reluctance to self-disclose". When discussing romantic relationships, the influence of adult attachment orientation is especially important $[19,20]$. So far, there are few studies in Chinese research that have focused on the effects of attachment in the romantic relationship of infertile couples.

Empathy is defined as a person's ability to understand another person's situation, to share in what another person is feeling, and act on that understanding in a helpful way [21, 22]. Empathy is a significant ingredient in the development of social relations because it could facilitate good communication and manage conflict events successfully in close relationships [23]. Natalie's study found that in the parents of newborn babies, the couples with high levels of empathy also had high levels of sexual and relationship satisfaction [24]. According to the result of the study of Sun et al. [25] study on how empathy and relationship type interact with pain, the pain test survey showed that romantic partners recovered faster than friends, and empathy may modulate psychological and physiological responses in romantic relationships [25]. The results of Lingdan's study also verified that empathy can lead to the enhancement of earlier posterity negativity (EPN) and late positive potential (LPP) components in brain processing signals due to pain signals received by partners; this explains the possible role of empathy in dealing with stress stimuli in marital relationships from the perspective of neurotic electrophysiology [26]. However, few studies have focused on the effect of empathy on the relationship between infertile couples, especially in Chinese populations.

The purpose of this study is to examine the associations between attachment orientation, empathy, 
and the relationship quality in a sample of infertile couples. The results of this study may be helpful to nurses in identifying such effects and providing baseline information to develop nursing interventions for couples facing fertility problems.

\section{Method}

\section{Participants}

This cross-sectional research was conducted on infertile couples who came to the First Affiliated Hospital Reproductive Medicine Centre of Zhengzhou University in Henan province from August to September 2020. The final sample was 168 couples (336 individuals). Based on the study of Hair et al, the sample size of path analysis is adequate if the participant number is between 100 to 150 [27]. According to that viewpoint, the sample size in our study is acceptable.

All of the couples meet the following criteria for inclusion: fit the definition of infertility and obtain the diagnosis from a clinician; married and in a heterosexual relationship; participate in the study voluntarily; no children, births or adoptions; experienced more than one cycle of assisted reproductive therapy; and able to understand Chinese well enough to complete the questionnaires. The exclusion criteria are a history of similar research, experiencing a major life event over the past 12 months, or a history of mental illness.

This protocol was approved by the clinical ethics committee from First Affiliated Hospital of Zhengzhou University. All the participants were informed of the objectives of this study and were assured that all the information they provided would only be used in the study. All of the respondents signed informed consent before filling out the questionnaire.

\section{Demographic information questionnaire}

A self-made questionnaire was designed to collect demographic information, such as the socio-demographics factors and information related to infertility. The socio-demographic section was constructed by age, educational background, economy state, and so on. The infertility-related section was constructed by duration of infertility, cause of infertility (male, female, both, unknown), and so on.

\section{Relationship quality}


The Relationship Quality scale is a sub-scale of Fertility Quality of Life (FertiQol), which was developed by the European Society of Human Reproduction and Embryology and the American Society of Reproductive Medicine [28]. This measure has been translated into 26 languages, including Chinese, and it is available free at http://www.fertiqol.org/. The Relationship quality scale is a subscale of the core FertiQol. It consists of 6 items scored according to 5 response categories, which shows the impact that fertility problems have on certain components of a relationship or partnership, such as sexuality, communication, and commitment. Cronbach's alpha in this study was 0.86 .

\section{Revised adult attachment scale}

The Adult Attachment Scale (AAS) was originally developed by Collins, and it was tested by Wu Weilin from China in 1996; however, the coefficient and retest reliability of the questionnaire are insufficient [29]. In this study, we used the revised AAS which was culturally adjusted by Chinese researchers to include attachment anxiety and attachment avoidance [30]. In this version, the scale consists of 13 items, which are rated on a 5-point Likert-type scale. 1 meaning the statement is very inconsistent to 5 meaning the statement is very consistent with the participant. The attachment anxiety and avoidance scale Cronbach alpha were 0.75 and 0.79 .

\section{Interpersonal Reactivity Index (IRI)}

The IRI scale was initially developed by Davis, but Taiwanese scholar Zhan Zhiyu later translated and revised the scale in Chinese to include a total of 22 questions [31]. A Likert 5-point rating method is adopted for each item, from 0 to 4 , respectively, meaning inappropriate to very appropriate. Cronbach's alpha in this study was 0.71 .

\section{Data collection and classification}

To identify any potential problems, we conducted a pre-investigation before the formal investigation. Some typographical errors were found in the pre-investigation, and all of them were corrected after researchers carefully checked the references. When administering the preliminary survey, we found that most of the surveyed couples could complete the questionnaire within 15-20 minutes, so we determined 
the time limit for the participants to complete the questionnaire.

Researchers invited infertile couples who met the inclusion criteria into a quiet conference room to voluntarily participate in the study. After signing the informed consent, the researchers gave the respondents standardized directions and asked the participants to finish the questionnaire in 20 minutes or less. The questionnaires were collected on the spot, and the researchers timely checked them for completeness. To ensure the integrity of the questionnaires, participants were asked to complete missing items immediately. To ensure the quality of the data, if any participants refuse to answer the questionnaire completely, we will eliminate the questionnaire. All the data was entered into the computer by Epi Data software using the double entry system. After a consistency check, we review the original material and modify the errors.

\section{Statistical analyses}

Descriptive statistics, chi-square tests, paired sample $t$-tests, independent sample $t$-tests, one-way ANOVA, and Pearson correlations were used to analyze general characteristics and variables. The independent variables were attachment anxiety, attachment avoidance, and empathy; the dependent variable was the relationship quality of female and male. We used hierarchical regression to examine the unique and combined contribution of the independent variables to relationship quality of couples. According to the result of Pearson correlations and stepwise regression, we set up the model (Fig. 1) to assess the actor and partner effects of independent variables on the relationship quality. We conducted path analysis using AMOS 24.0 software, and path analysis model test indexes include ( $\left.\chi^{2} / \mathrm{df}\right)$, goodness of fit index (GFI), comparative fit index (CFI), Tucker-Lewis index (TLI), and the root mean square error of approximation (RMSEA). The criteria for a well-fit model are that the values of $\left(\chi^{2} / \mathrm{df}\right)<5$, GFI, CFI, and TLI are higher than 0.9 and the RMSEA is lower than 0.05 [32].

\section{Results}

\section{Demographic and infertility related characteristics}

The demographic and infertility related characteristics of males and females are presented in Table 1. On 
average, wives aged 35 years older constituted for $39.3 \%$ of the participants and husbands aged 35 years older accounted for $47.0 \%\left(\chi^{2}=16.84, P<0.001\right)$. The wives that possessed an academic education was $53 \%$, and the husbands that had the same educational level was $53.6 \%\left(\chi^{2}=14.58, P<0.001\right)$.

Table 1 Demographic and infertility characteristics $(\mathrm{N}=336)$

\begin{tabular}{|c|c|c|c|c|c|}
\hline Variable & Categories & $\begin{array}{l}\text { Male } \\
(\mathrm{n}=168)\end{array}$ & $\begin{array}{l}\text { Female } \\
(\mathrm{n}=168)\end{array}$ & $\chi^{2}$ & $P$ \\
\hline \multirow[t]{2}{*}{$\operatorname{Age}(\mathrm{Y})$} & $\leq 35$ & $89(53.0)$ & $102(60.7)$ & 16.84 & $<0.001$ \\
\hline & $>35$ & $79(47.0)$ & $66(39.3)$ & & \\
\hline \multirow[t]{2}{*}{ Educational level } & None academic & $78(46.4)$ & $79(47.0)$ & 14.58 & $<0.001$ \\
\hline & Academic & $90(53.6)$ & $89(53.0)$ & & \\
\hline \multirow[t]{3}{*}{ Family monthly income } & $<5000 \mathrm{RMB}$ & $23(13.7)$ & & & \\
\hline & 5000-8000 RMB & $103(61.3)$ & & & \\
\hline & $>8000 \mathrm{RMB}$ & $42(25.0)$ & & & \\
\hline \multirow{2}{*}{ Duration of Marriage (Y) } & $<3$ & $70(41.7)$ & & & \\
\hline & $\geqslant 3$ & $98(58.3)$ & & & \\
\hline \multirow[t]{2}{*}{ Duration of Infertility (Y) } & $<3$ & $77(45.8)$ & & & \\
\hline & $\geqslant 3$ & $91(54.2)$ & & & \\
\hline \multirow[t]{2}{*}{ Number of infertility treatment cycles } & $<3$ & $115(68.5)$ & & & \\
\hline & $\geqslant 3$ & $53(31.5)$ & & & \\
\hline \multirow[t]{2}{*}{ Type of infertility } & Primary & $103(61.3)$ & & & \\
\hline & Secondary & $65(38.7)$ & & & \\
\hline \multirow[t]{4}{*}{ Cause of infertility } & Male & $46(27.4)$ & & & \\
\hline & Female & $77(45.8)$ & & & \\
\hline & Both & $21(12.5)$ & & & \\
\hline & Unknown & $24(14.3)$ & & & \\
\hline
\end{tabular}

Data are presented as "n (\%)".

Out of $31.5 \%$ infertile couples who had experienced more than 3 cycles of assisted reproductive technology (ART) treatment. $27.4 \%$ of males were the cause of infertility; $45.8 \%$ of females were the cause of infertility; $12.5 \%$ was attributed to both, and $14.3 \%$ were unknown.

\section{Common method biases}

In SPSS software, the Harman test was used to access common method bias, and all variables were included into exploratory factor analysis. The results of the unrotated factor analysis showed that the variation of the first factor was $28.64 \%$, which was less than the critical value of $40 \%$. Therefore, there was no serious common method bias in this study. 


\section{Relationship quality, attachment orientation and empathy}

The gender differences in relationship quality, attachment orientation, and empathy of wives and husbands are presented in Table 2. Wives reported lower levels of relationship quality $(t=7.66, P<0.001)$ and attachment anxiety $(t=5.59, P<0.001)$ and higher levels of attachment avoidance $(t=-7.69, P<$ 0.001) compared with their husband's results. The empathy scores of the husbands and their wives were similar $(t=-0.78, P=0.435)$. The results of single factor analysis of demographic characteristics are shown in Table 3. The duration of infertility was the only factor which was statistically significant both in the wives' relationship quality $(t=4.81, P=0.03<0.05)$ and the husbands' relationship quality $(t=5.87$, $P=0.02<0.05)$. The empathy in wives was correlated with both their own relationship quality $(\mathrm{r}=0.492$, $P<0.001)$ and their husbands' relationship quality $(\mathrm{r}=0.334, P<0.001)$. Empathy in husbands was also correlated with both their own relationship quality $(\mathrm{r}=0.325, P<0.001)$ and the husband's marital satisfaction $(\mathrm{r}=0.405, P<0.001)($ Table 4$)$.

Table 2 Gender differences in relationship quality, adult attachment, and empathy

\begin{tabular}{lllll}
\hline Variable & Male $(\mathrm{n}=168)$ & Female $(\mathrm{n}=168)$ & $t$ & $P$ \\
\hline Relationship quality & $70.73 \pm 13.48$ & $60.71 \pm 15.85$ & 7.66 & $<0.001$ \\
Attachment anxiety & $17.68 \pm 3.51$ & $15.56 \pm 3.74$ & 5.59 & $<0.001$ \\
Attachment avoidance & $14.65 \pm 4.43$ & $18.04 \pm 3.65$ & -7.69 & $<0.001$ \\
Empathy & $46.85 \pm 13.33$ & $47.90 \pm 12.85$ & -0.78 & 0.435 \\
\hline Vald
\end{tabular}

Values are presented as mean \pm SD.

Table 3 Analysis of infertile couples' relationship quality in demographic and clinical data

\begin{tabular}{|c|c|c|c|c|c|c|}
\hline Categories & $\begin{array}{l}\text { Relationship } \\
\text { quality of male }\end{array}$ & $t / \mathrm{F}$ & $P$ & $\begin{array}{l}\text { Relationship quality of } \\
\text { female }\end{array}$ & $t / \mathrm{F}$ & $P$ \\
\hline \multicolumn{7}{|l|}{ Age $(Y)$} \\
\hline$\leq 35$ & $72.07 \pm 14.09$ & 1.86 & 0.17 & $61.25 \pm 16.43$ & 0.30 & 0.58 \\
\hline$>35$ & $69.23 \pm 12.68$ & & & $59.88 \pm 15.01$ & & \\
\hline \multicolumn{7}{|l|}{ Educational level } \\
\hline None academic & $70.58 \pm 13.18$ & 0.02 & 0.89 & $59.09 \pm 16.23$ & 1.57 & 0.21 \\
\hline Academic & $70.86 \pm 13.81$ & & & $62.16 \pm 15.46$ & & \\
\hline \multicolumn{7}{|c|}{ Family monthly in-come } \\
\hline$<5000 \mathrm{RMB}$ & $69.32 \pm 12.26$ & 0.49 & 0.61 & $56.91 \pm 14.34$ & 1.07 & 0.35 \\
\hline 5000-8000 RMB & $70.36 \pm 13.14$ & & & $61.97 \pm 16.22$ & & \\
\hline$>8000 \mathrm{RMB}$ & $72.43 \pm 15.02$ & & & $59.71 \pm 15.67$ & & \\
\hline \multicolumn{7}{|c|}{ Duration of Marriage (Y) } \\
\hline$<3$ & $70.39 \pm 12.79$ & 0.08 & 0.78 & $61.41 \pm 16.06$ & 0.23 & 0.63 \\
\hline$\geqslant 3$ & $70.98 \pm 14.01$ & & & $60.21 \pm 15.77$ & & \\
\hline
\end{tabular}




\begin{tabular}{|c|c|c|c|c|c|c|}
\hline \multicolumn{7}{|c|}{ Duration of Infertility (Y) } \\
\hline$<3$ & $73.43 \pm 13.89$ & \multirow[t]{2}{*}{5.87} & \multirow[t]{2}{*}{0.02} & $63.60 \pm 15.28$ & \multirow[t]{2}{*}{4.81} & \multirow[t]{2}{*}{0.03} \\
\hline$\geqslant 3$ & $68.45 \pm 12.76$ & & & $58.27 \pm 16.01$ & & \\
\hline \multicolumn{7}{|c|}{ Number of infertility treatment cycles } \\
\hline$<3$ & $71.24 \pm 13.62$ & \multirow[t]{2}{*}{0.52} & \multirow[t]{2}{*}{0.47} & $61.72 \pm 16.56$ & \multirow[t]{2}{*}{1.47} & \multirow[t]{2}{*}{0.22} \\
\hline$\geqslant 3$ & $69.63 \pm 13.24$ & & & $58.53 \pm 14.11$ & & \\
\hline \multicolumn{7}{|c|}{ Type of infertility } \\
\hline Primary & $71.77 \pm 14.18$ & \multirow[t]{2}{*}{1.57} & \multirow[t]{2}{*}{0.21} & $61.96 \pm 15.94$ & \multirow[t]{2}{*}{1.65} & \multirow[t]{2}{*}{0.20} \\
\hline Secondary & $69.09 \pm 12.22$ & & & $58.74 \pm 15.64$ & & \\
\hline \multicolumn{7}{|c|}{ Cause of infertility } \\
\hline Male & $69.29 \pm 13.58$ & \multirow[t]{4}{*}{0.94} & \multirow[t]{4}{*}{0.42} & $61.91 \pm 17.85$ & \multirow[t]{4}{*}{0.85} & \multirow[t]{4}{*}{0.47} \\
\hline Female & $72.53 \pm 13.19$ & & & $61.64 \pm 15.44$ & & \\
\hline Both & $70.35 \pm 13.73$ & & & $59.90 \pm 14.04$ & & \\
\hline Unknown & $68.08 \pm 14.06$ & & & $56.17 \pm 14.63$ & & \\
\hline
\end{tabular}

Table 4 Correlations among predictors and outcomes in dyads for male and female

\begin{tabular}{lll}
\hline Categories & Relationship quality of male & Relationship quality of female \\
\hline Male & & \\
Attachment anxiety & $-0.219^{* *}$ & -0.109 \\
Attachment avoidance & $-0.315^{* *}$ & -0.139 \\
Empathy & $0.325^{* *}$ & $0.405^{* *}$ \\
Female & & \\
Attachment anxiety & -0.144 & $-0.230^{* *}$ \\
Attachment avoidance & $-0.051^{* * *}$ & $-0.271^{* *}$ \\
Empathy & $0.334^{* *}$ & $0.492^{* *}$ \\
\hline$*$ P &
\end{tabular}

${ }^{* *} P<0.001$ found to be statistically significantly.

\section{Hierarchical regression}

Table 5 and Table 6 presents the results of the regression analysis. According to the result of single factor analysis of demographic characteristics and Pearson correlations, duration of infertility was entered into the regression of relationship quality. The results showed that the duration of infertility was not a significant cause of relationship quality among couples. The variables explained $42 \%$ of the difference in female's relationship quality, and $29 \%$ of the difference in male's relationship quality.

Table 5 Hierarchical regression of female relationship quality

\begin{tabular}{lllllllll}
\hline Variables & \multicolumn{7}{l}{ First step } & \multicolumn{5}{l}{ Second step } \\
\cline { 2 - 8 } & $\beta$ & S.E & $t$ & $P$ & $\beta$ & S.E & $t$ & $P$ \\
\hline
\end{tabular}




\begin{tabular}{|c|c|c|c|c|c|c|c|c|}
\hline \multicolumn{9}{|l|}{ Female } \\
\hline Duration of infertility & -1.20 & -0.04 & -0.43 & 0.56 & -0.69 & -0.02 & -0.36 & 0.72 \\
\hline Attachment anxiety & -0.91 & -0.22 & -3.26 & $<0.05$ & -0.75 & -0.18 & -2.95 & $<0.05$ \\
\hline Attachment avoid-ance & -0.87 & -0.20 & -2.95 & $<0.05$ & -0.69 & -0.16 & -2.59 & $<0.05$ \\
\hline Empathy & 0.56 & 0.45 & 7.44 & $<0.001$ & 0.53 & 0.43 & 6.99 & $<0.001$ \\
\hline \multicolumn{9}{|l|}{ Male } \\
\hline Empathy & & & & & 0.37 & 0.31 & 5.11 & $<0.001$ \\
\hline $\mathrm{F}$ & $20.34^{* *}$ & & & & $23.99^{* *}$ & & & \\
\hline$R^{2}$ & 0.33 & & & & 0.42 & & & \\
\hline$\Delta R^{2}$ & & & & & $0.09^{* *}$ & & & \\
\hline
\end{tabular}

${ }^{* *} P<0.001$ found to be statistically significantly

Table 6 Hierarchical regression of male relationship quality

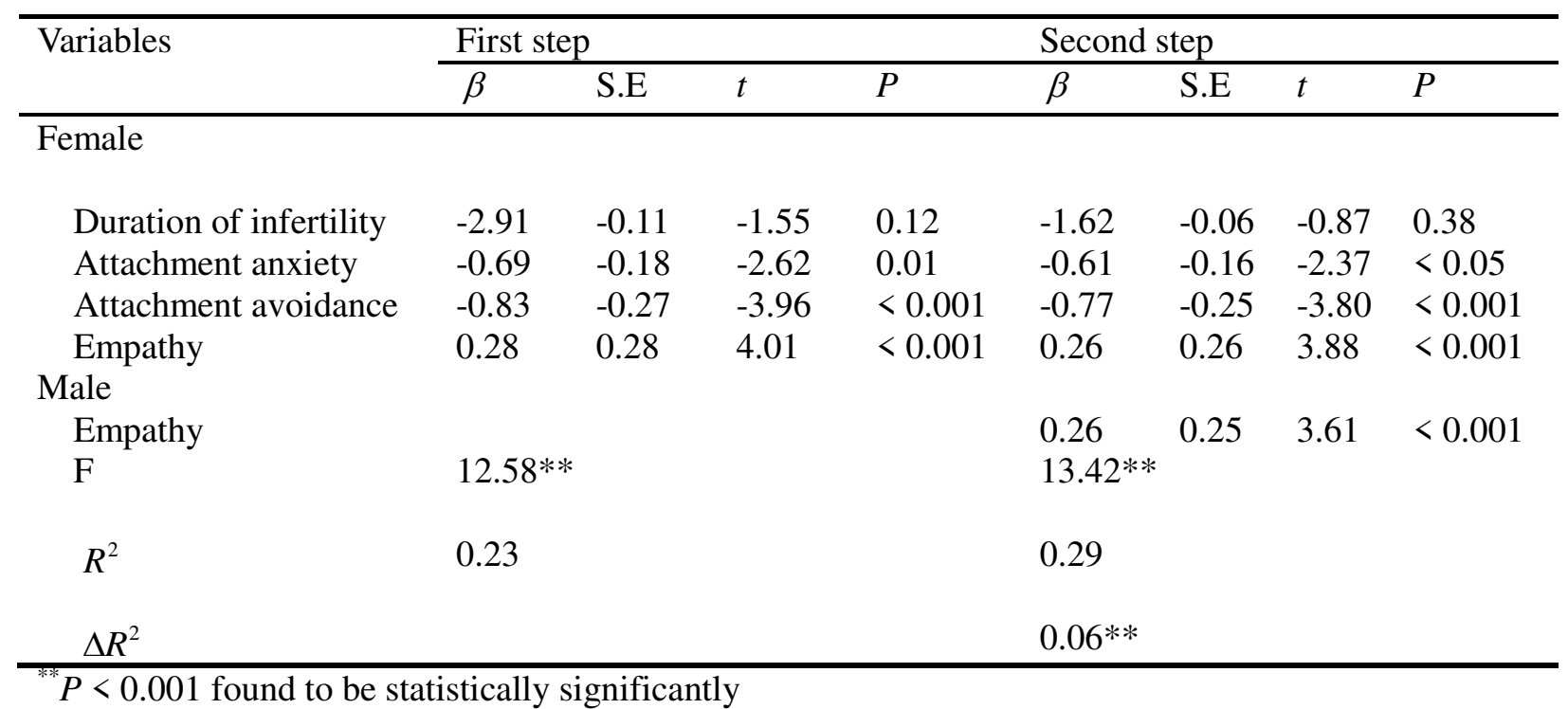

\section{Path analysis}

To access the infertile couples' relationship quality and binary interaction relations between the influencing factors, we used Amos 24.0 software to analyze the structural equation model shown in Fig. 1. The model indexes reach the standard criteria: $\chi^{2} / \mathrm{df}=1.18, \mathrm{GFI}=0.97, \mathrm{CFI}=0.97, \mathrm{TLI}=0.96, \mathrm{RMSEA}=$ 0.03 .

\section{Discussion}

The objectives of this study were to evaluate whether attachment orientation and empathy were factors 
affecting the quality of the relationship between infertile Chinese couples, and assess a model of the interactions of these factors on the quality of relationships. The data of the present research verified the significant effects of attachment orientation and empathy on the quality of the relationship. However, only the empathy of infertile couples has actor and partner effects on the quality of the relationship. The survey data basically supported the purpose of this study. To the best of our knowledge, this is the first time that the attachment orientation and empathy in infertile Chinese couples was investigated. In addition, evaluate the effect of these variables on the quality of relationships was also an innovative component of the present research.

ART is generally divided into two types, one is in vitro fertilization and embryo transfer technology (IVF-ET) and the other is Artificial Insemination with semen from either the husband or a donor (AIH/AID). After the development of in vitro embryo screening and selection technology the clinical pregnancy rate of IVF-ET was reported to be much higher than AIH/AID [33]. Based on the limited literature available on the subject, the IVF-ET clinical pregnancy rate was not more than $60 \%$ and the rate of AIH/AID was less than $30 \%[34,35]$. Similar to the above results, according to data reported in 2016 by the Society for Assisted Reproductive Technology (SART), among woman under the age of 35 years, following ART treatment the live-born delivery rates were less than $50 \%$. The success rate for woman over 35 was much lower than that [36]. The success rate of assisted reproduction is similar to the success rate of flipping a coin in a positive direction. Infertile couples, especially those with more than one cycle, often experience a rollercoaster of emotions during assisted reproduction treatment. How can infertile couples maintain healthy relationships despite such emotional highs and lows? This means that our research has some social implications.

The same like previous studies about relationship quality of infertile couples ,the relationship quality of wives was lower than their husbands $[37,38]$. The results indicate that women are likely to be less confident than men in their relationship when they experience repeated pregnancy failures. This may be related to the influence of Chinese culture and the one-child policy introduced by the government in the 1980s, where fertility is traditionally one of the role expectations of wives in the family environment and 
giving birth to a baby boy is important to the continuity of a family [39]. Despite the importance of girls for spreading the rearing of the family communicated by social media such as Tik-Tok and WeChat, the importance of giving birth to boys is still deeply rooted in most rural areas. The one-child policy resulted in some families having only one male in the next generation of child-bearing age. If a woman finds it difficult to have a child in such a family or to have a boy, it may affect her judgment on the quality of the relationship with her husband. The fact that role identity and role expectations collide among women may explain the lower relationship quality score among the women than the men. Moreover, though there were no significant effects in the duration of infertility on relationship quality, the $t$-test result showed significant differences among groups. This suggests that couples who had been diagnosed with infertility problems for longer than three years could not judge the quality of their relationship as well as couples who were infertile for less than three years.

According to the results of the gender differences in adult attachment, compared with their spouse, infertile Chinese women are more prone to take attachment avoidance strategy in dealing with adult attachment relationships, while men are more likely to show attachment anxiety than their wives. Avoidant attachment means that women are unwilling to reveal their inner pain to their partners and choose to be more introvertive in dealing with fertility problems. This is similar to the previous qualitative interview results of Chinese infertile women, who chose to avoid communication in order to alleviate their pain, which can cause more loneliness [14]. The results of this study show that attachment avoidance is a negative predictor of relationship quality. One thing that may be helpful in solving this problem is encouraging infertile women to openly share their feelings with their husbands. After all, previous studies have shown that self-disclosure promotes coping strategies among infertile women [40]. Based on the definition of attachment anxiety, we could infer that infertile husbands are more likely to show the attachment anxiety; they are eager to get positive interactive responses from their partners. In China, male chauvinism is not uncommon, and the frustration of not being able to have children may increase attachment anxiety in men. This means that males with infertility express their points more directly in relationships, and they do not want fertility problems to interfere with their happiness. Chinese men traditionally like to maintain con- 
trol of any problems within the family structure.

The results of this study showed that the wives' ability to empathize was higher than that of the husbands' ability; this means that wives may have a more innate ability than husbands to be understanding and compassionate, which are very important for the relationship quality while trying to solve fertility problems. Women mainly receive the assisted reproductive technology treatment and seem to be the ones most blamed for issues in the traditional Chinese family environment. The findings suggest that infertile women fare worse than infertile men in being misunderstood by their partners. Developing interventions is vital. An example is, asking the partners of infertile patients who are receiving counseling, to participate in the psychological intervention. This is so that they understand the importance of having empathy for their partner in the regulation of their emotions and the management of the relationship. Another intervention in clinical work, is to organize regular training courses on empathy for couples. Infertile couples will be able to learn the importance of mutual understanding and support for the success of their pregnancy. Another is to invite an empathetic infertile couple who have successfully given birth to a child, to attend a meeting and assist infertile couples with their relationship problems. These can be beneficial in helping infertile women get effective social support and enhance their relationship confidence. This could be valuable in helping families with infertility to maintain stability and harmony until effective medical help is available and may point the way for future research.

\section{Conclusion}

The findings in this research suggest that the wife should be encouraged to reveal her thoughts to the object of attachment and the husband needs to increase empathy, so as to understand the difficulty of the wife and promote social support for the wife. Infertile couples should understand each other and expressing understanding behavior is conducive to the harmony of the relationship. There are still limitations in our study. Although the Reproductive Center of the First Affiliated Hospital of Zhengzhou University is one of the largest reproductive treatment centers in China, the subjects of our study were limited to infertile couples who came to the hospital, and the infertile couples who did not come to the hospital and those in other provinces were not included in the study. One of our limitations is that the research on the impact 
of relationship quality of infertile couples does not include the impact of social support in traditional settings, such as parents. Moreover, in the present study, we mixed up the causes of infertility to analysis the attachment of adult couples. The percentage of infertility due to causes affecting males was lower than those affecting females. This may have affected our perception of male attachment orientation. Therefore, future studies should include those variables and focus on the attachment orientation of men when only the male is the cause of the infertility.

\section{List of abbreviations}

\begin{tabular}{ll}
\hline Abbreviations & Extensions \\
\hline FertiQol & Fertility Quality of Life \\
EPN & Earlier Posterity Negativity \\
LPP & Late Positive Potential \\
AAS & Adult Attachment Scale \\
IRI & Interpersonal Reactivity Index \\
GFI & Goodness of Fit Index \\
TLI & Tucker-Lewis Index \\
RMSEA & The Root Mean Square Error of Approximation \\
ART & Assisted Reproductive Technology \\
IVF-ET & In Vitro Fertilization and Embryo Transfer Technology \\
AIH & Artificial Insemination with Semen from Husband \\
AID & Artificial Insemination with Semen from Donor \\
\hline
\end{tabular}

\section{Declarations}

\section{Ethics approval and consent to participate}

The protocol of this study was approved by the clinical ethics committee from First Affiliated Hospital of Zhengzhou University. 


\section{Consent for publication}

Written informed consent for publication was obtained from all participants.

\section{Availability of data and materials}

All data generated or analysed during this study are included in this article.

\section{Competing interests}

The authors declare that they have no competing interests.

\section{Funding}

None

\section{Authors' contributions}

All authors contributed equally.

\section{Acknowledgements}

We thank the infertile couples who made this study possible for their participation in this study. We also thank Feijing Zhou, Zhimin Sun for their help in collecting specimens.

\section{References}

1. World Health Organization. Infertility definitions and terminology 2020 [Available from: http://www.who.int/reproductivehealth/topics/infertility/definitions/en/.

2. Meng Q, Zhang Y, Ren A. Infertility rate in married couples of reproductive age in China: a systematic review and Meta-analysis. Chin J Epidemiol. 2013;34(8):826-31.

3. Rooney KL, Domar AD. The relationship between stress and infertility. Dialogues Clin Neurosci. 2018;20(1):41-7.

4. Kahyaoglu Sut H, Balkanli Kaplan P. Quality of life in women with infertility via the FertiQoL and the Hospital Anxiety and Depression Scales. Nurs Health Sci. 2015;17(1):84-9.

5. Jiang Y, Liu J, Han J. Investigation on the level of stigma and its influencing factors in female infertility patients. Chin J Nurs. 2018;53(6):698-703.

6. Ergin RN, Polat A, Kars B, Öztekin D, Sofuoğlu K, Çalışkan E. Social stigma and familial attitudes 
related to infertility. Turk J Obstet Gynecol. 2018;15(1):46-9.

7. Lotti F, Maggi M. Sexual dysfunction and male infertility. Nature Reviews Urology. 2018;15(5):287-307.

8. Kloss JD, Perlis ML, Zamzow JA, Culnan EJ, Gracia CR. Sleep, sleep disturbance, and fertility in women. Sleep Med Rev. 2015;22:78-87.

9. Palnitkar G, Phillips CL, Hoyos CM, Marren AJ, Bowman MC, Yee BJ. Linking sleep disturbance to idiopathic male infertility. Sleep Med Rev. 2018;42:149-59.

10. Rahebi SM, Rahnavardi M, Rezaie-Chamani S, Nazari M, Sabetghadam S. Relationship between domestic violence and infertility. East Mediterr Health J. 2019;25(8):537-42.

11. Yu L, Sheng Y, Peng T. Marriage quality and sexual life of infertility couples. Chinese Journal of Human Sexuality. 2012;21(3):43-5,53.

12. Afshani SA, Mohammadi SMRG, Khani P, Khosravi A. Role of resilience training on compromising of infertile couples' applicant for divorce: A cross-sectional study. Int J Reprod Biomed. 2020;18(3):193-208.

13. Li Y, Zhang X, Shi M, Guo S, Wang L. Resilience acts as a moderator in the relationship between infertility-related stress and fertility quality of life among women with infertility: a cross-sectional study. Health and Quality of Life Outcomes. 2019;17(1):38.

14. Tiu MMH, Hong JYF, Cheng VS, Kam CYC, Ng BTY. Lived experience of infertility among Hong Kong Chinese women. International Journal of Qualitative Studies on Health and Well-being. 2018;13(1):1554023.

15. Bowlby J. Attachment and loss: Retrospect and prospect. Am J Orthopsychiatry. 1982;52(4):664-78.

16. Khalifian CE, Barry RA. Trust, attachment, and mindfulness influence intimacy and disengagement during newlyweds' discussions of relationship transgressions. J Fam Psychol. 2016;30(5):592-601.

17. Donarelli Z, Lo Coco G, Gullo S, Marino A, Volpes A, Allegra A. Are attachment dimensions associated with infertility-related stress in couples undergoing their first IVF treatment? A study on the individual and cross-partner effect. Hum Reprod. 2012;27(11):3215-25. 
18. Skvirsky V, Taubman - Ben-Ari O, Ben Shlomo S, Azuri J, Horowitz E. Contributors to women's perceived stress at the start of assisted reproductive technology. The Journal of Psychology. 2019;153(1):23-36.

19. Brenner I, Bachner-Melman R, Lev-Ari L, Levi-Ogolnic M, Tolmacz R, Ben-Amitay G. Attachment, sense of entitlement in romantic relationships, and sexual revictimization among adult CSA survivors. Journal of Interpersonal Violence. 2019:0886260519875558.

20. Campbell L, Stanton SCE. Adult attachment and trust in romantic relationships. Current Opinion in Psychology. 2019;25:148-51.

21. Abbasi K. Why empathy is an upside-down concept. J R Soc Med. 2017;110(9):347.

22. Howick J, Rees S. Overthrowing barriers to empathy in healthcare: empathy in the age of the Internet. J R Soc Med. 2017;110(9):352-7.

23. Hastings TJ, Kavookjian J, Ekong G. Associations among student conflict management style and attitudes toward empathy. Currents in Pharmacy Teaching and Learning. 2019;11(1):25-32.

24. Rosen NO, Mooney K, Muise A. Dyadic empathy predicts sexual and relationship well-being in couples transitioning to parenthood. J Sex Marital Ther. 2017;43(6):543-59.

25. Sun B, Zhou L, Xiao W, Zhao X, Zhang W, Li W. Accurate empathy of romantic partners increases pain ratings but promotes recovery. Psychol Res Behav Manag. 2018;11:403-10.

26. Wu L, Kirmse U, Flaisch T, Boiandina G, Kenter A, Schupp HT. Empathy, pain and attention: Cues that predict pain stimulation to the partner and the self capture visual attention. Front Hum Neurosci. 2017; 11:465.

27. Hair JF, Black WC, Babin BJ, Anderson RE, Tatham RL. Multivariate data analysis: A global perspective. 7 ed. Prentice hall Upper Saddle River, NJ: Prentice Hall; 1998.

28. Boivin J, Takefman J, Braverman A. The fertility quality of life (FertiQoL) tool: development and general psychometric properties†. Hum Reprod. 2011;26(8):2084-91.

29. Collins NL. Working models of attachment: Implications for explanation, emotion, and behavior. JPSP. 1996;71(4):810-32. 
30. Du J, Wang H, Li Y. The revision of adult attachment scale (AAS) in Chinese college students sample. Journal of Huzhou University. 2015;37(1):63-9.

31. Zhang F, Dong Y, Wang K, Zhan Z, Xie L. Reliability and validity of the Chinese version of the interpersonal reactivity index-C. Chinese Journal of Clinical Psychology. 2010;18(2):155-7.

32. Wu M. Structural equation model: The operation and application of AMOS. 2 ed. Chongqing: Chongqing University Press; 2010.

33. Zhou F, Dong Y. Psychological stress is related to treatment outcome in women undergoing in-vitro fertilization and Embryo transplantation. Int J Clin Exp Med. 2016;9(4):7481-8.

34. Lee J, Hwang S, Lee J, Yoo J, Jang D, Hwang K, et al. Effect of insemination timing on pregnancy outcome in association with female age, sperm motility, sperm morphology and sperm concentration in intrauterine insemination. J Obstet Gynaecol Res. 2018;44(6):1100-6.

35. Li X-f, Fan H-r, Sheng Y, Sun M. Factors affecting the success rate of artificial insemination with donor sperm. National journal of andrology. 2015;21(3):234-8.

36. Toner JP, Coddington CC, Doody K, Van Voorhis B, Seifer DB, Ball GD, et al. Society for Assisted Reproductive Technology and assisted reproductive technology in the United States: a 2016 update. Fertil Steril. 2016;106(3):541-6.

37. Goker A, Yanikkerem E, Birge O, Kuscu NK. Quality of life in Turkish infertile couples and related factors. Hum Fertil. 2018;21(3):195-203.

38. Zhou F. The relation of infertility related stress and quality of life in infertile couples [Master's thesis]. Zhengzhou: Zhengzhou University; 2016.

39. Zhu J. Differences in role expectations and conflicts between husband and wife-A case study of dual-career families in Beijing [Master's thesis]. Beijing: Renmin University of China; 2008.

40. Mosalanejad L, Khodabakhshi Koolaee A, Morshed Behbahani B. Looking out for the secret wound: the effect of e-cognitive group therapy with emotional disclosure on the status of mental health in infertile women. Int J Fertil Steril. 2012;6(2):87-94. 


\section{Figure legend}

Fig. 1. Path diagram of empathy, attachment orientation and relationship quality. 
Figures

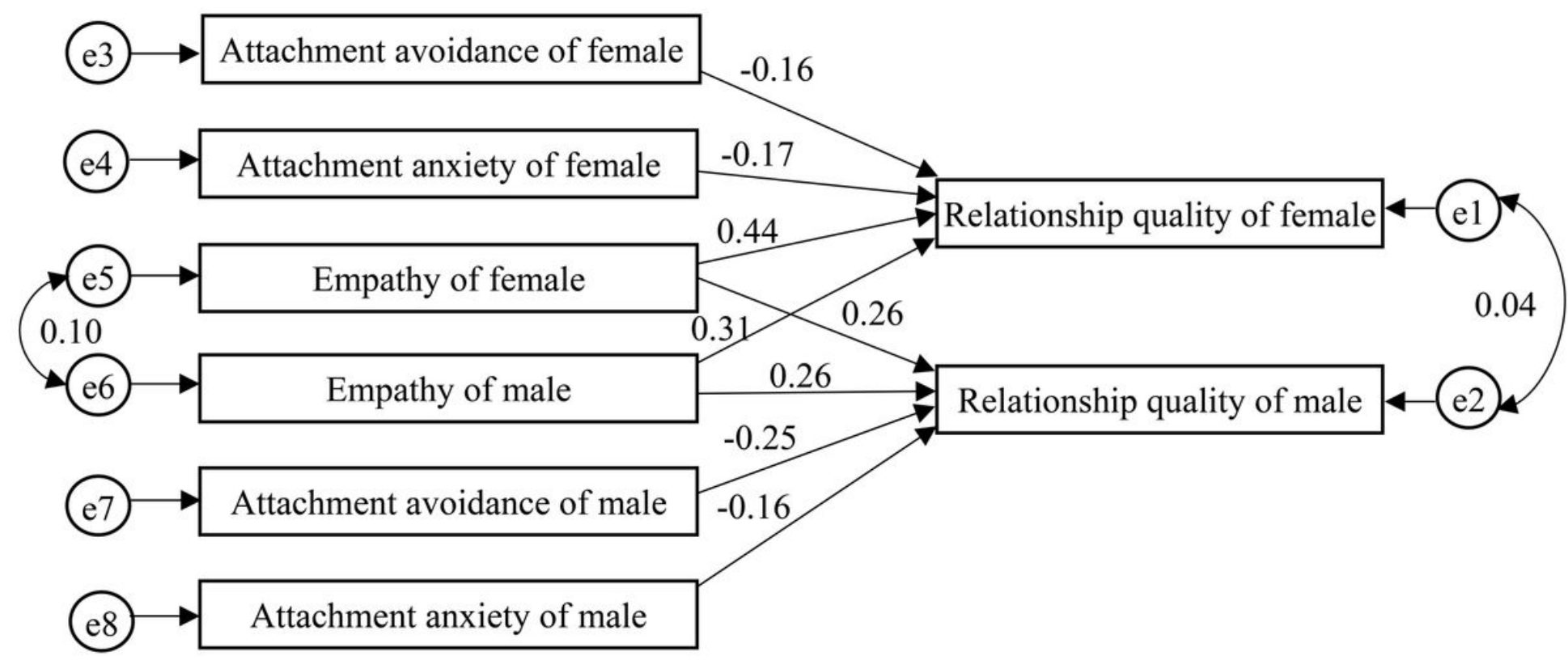

Figure 1

Path diagram of empathy, attachment orientation and relationship quality. 